\title{
Decreased Level of Neuropeptide Y Is Associated With Gastroparesis in Male Diabetic Rats
}

\author{
Rebecca Smiley $^{\mathrm{a}}$, Richard McCallum ${ }^{\mathrm{b}}$, Mohammed Showkat Alia, c
}

\begin{abstract}
Background: Substance P (SP) and neuropeptide Y (NPY), excitatory and inhibitory neuropeptides, respectively, may impact gastric motility in patients with diabetic mellitus (DM). We investigated these neuropeptide levels, NPY receptors, total nitric oxide synthase (NOS) levels, and neuronal NOS alpha (nNOS $\alpha$ ) activation status and levels in streptozotocin-induced type I diabetes in male rats.
\end{abstract}

Methods: Rats were grouped based on serum glucose and gastric emptying time: normal untreated control (CM), diabetic (DM) and diabetic gastroparesis $(\mathrm{DM}+\mathrm{GP})$. Neuropeptide serum levels were determined by enzyme-linked immunosorbent assay (ELISA). Sodium dodecyl sulphate-polyacrylamide gel electrophoresis (SDSPAGE) and western blotting measured NPY receptors, Y1 and Y2, and $\mathrm{nNOS} \alpha$ expression. Low-temperature SDS-PAGE followed by western blotting was used to measure the dimerization of $n N O S \alpha$. An NOS colorimetric assay kit was used to measure total NOS activity.

Results: SP levels were significantly decreased $(\mathrm{P}<0.05)$ in $\mathrm{DM}$ and $\mathrm{DM}+\mathrm{GP}$ compared to CM. NPY levels were significantly decreased $(\mathrm{P}<0.05)$ in DM compared to $\mathrm{CM}$, and DM + GP had a more significantly decreased NPY when compared to both DM and CM. Protein levels of neuropeptide receptor Y1 (NPY-Y1) in the smooth muscle of pylorus were significantly increased in DM, but not in DM + GP when compared to CM. Neuropeptide receptor Y2 (NPY-Y2) was not detected. Changes in nNOS $\alpha$ activity and their protein levels, as well as total NOS activity, among the groups were insignificant.

Conclusions: Increased expression of pylorus NPY-1R and decreased serum NPY are present in diabetes. A more pronounced decreased serum NPY with no NPY-1R upregulation in pyloric smooth muscle is associated with gastroparesis. NPY levels show no relationship with $\mathrm{nNOS} \alpha$ levels, their activation status, or total NOS activity in

Manuscript submitted August 20, 2020, accepted October 21, 2020

Published online December 23, 2020

aDepartment of Clinical Investigation, William Beaumont Army Medical Center, 5005 N. Piedras Street, El Paso, TX 79920-5001, USA

${ }^{b}$ Department of Internal Medicine, Texas Tech Health Science Center, Paul L. Foster School of Medicine, 4800 Alberta Ave., El Paso, TX 79905-2709, USA ${ }^{\mathrm{c} C}$ Corresponding Author: Mohammed Showkat Ali, Department of Clinical Investigation, William Beaumont Army Medical Center, 5005 N. Piedras Street, El Paso, TX 79920-5001, USA. Email: moahmmed.s.ali6.civ@mail.mil

doi: https://doi.org/10.14740/gr1322 pyloric smooth muscle. These data suggest a pathophysiological role of severely depleted NPY and absence of NPY-Y1 upregulation for gastroparesis phenotype.

Keywords: Neuropeptide; Substance P; Diabetic gastroparesis

\section{Introduction}

Gastroparesis, a syndrome characterized by delayed gastric emptying, occurs in a significant number of diabetic patients ranging from $30 \%$ to $40 \%$ with long-standing type I and type II diabetes [1]. The gastrointestinal (GI) tract contains its own local nervous system referred to as the enteric nervous system (ENS) and is involved in digestive tract motility. Reports have demonstrated that neuroendocrine peptides, including substance P (SP) and neuropeptide Y (NPY), influence GI motor or sensory function and regulate GI transit and motility [2-4].

SP, an 11-amino acid orexigenic neuropeptide, and its receptors neurokinin-1 (NK1) and neurokinin-2 (NK2), have been shown to excite GI motor activity in virtually all regions and layers of the mammalian gut [5]. SP concentrations were found to be significantly lower in the plasma of patients with type I diabetes as compared to healthy controls [6]. Moreover, SP deficiency has been shown to result in the loss of interstitial cells of Cajal (ICC) and decreased neuronal nitric oxide synthase (nNOS) in patients with type II diabetes [7].

NPY, a 36-amino acid peptide, is a member of the pancreatic polypeptide family which acts through a series of Gprotein coupled receptors. There are four NPY receptor subtypes in humans: NPY receptor Y1 (NPY-Y1), NPY receptor Y2 (NPY-Y2), NPY receptor Y4 (NPY-Y4) and NPY receptor Y5 (NPY-Y5) [8]. Rats have similar NPY receptor subtypes (https://www.guidetopharmacology.org/GRAC/FamilyDispla yForward? familyId=46). A number of experimental findings imply that NPY has an important pathophysiological role in diabetes. Imai et al [9] reported that pancreatic islets from NPYdeficient mice had higher basal insulin secretion (1.5-fold) which leads to higher serum insulin levels (2.0-fold) compared with controls fed ad libitum. In another study, overexpression of NPY via a recombinant adenoviral vector in mice with triple deletion of NPY-Y1, NPY-Y2 and NPY-Y4 receptors prevented NPY-induced hyperinsulinemia [10], suggesting that these receptors are essential for NPY effects on the central regulation of circulating insulin levels. Unlike the type II diabetes 
mouse model, a rat type I diabetic study determined that NPY induced hyperinsulinemia in pancreatic islets of Langerhans in normal rats, but in diabetic rats, there was little or no NPY effect [11], probably due to beta cell destruction which results in diminished insulin production. Reports of NPY effects in diabetic gastroparesis are sparse. However, erythromycin, a drug widely used to treat gastroparesis in humans because of its ability to accelerate gastric emptying, has been reported to upregulate dopamine D3 and NPY-Y5 receptor genes, suggesting that these genes are involved in prokinetic gastric motility [12].

Nitric oxide (NO), a gaseous signaling molecule synthesized by NOS, is involved in regulation of a vast range of physiological processes, including the inhibitory neurotransmitter for gastric motility. There are three isoforms of NOS: neuronal (nNOS), endothelial (eNOS) and inducible (iNOS). Among these isoforms, neuronal nitric oxide synthase alpha $(\mathrm{nNOS} \alpha)$ is essential to normal gastric motility function [13]. A study comparing wild type and $\left(\mathrm{nNOS}^{-/-}\right)$mice demonstrated that the targeted genomic deletion of $\mathrm{nNOS}\left(\mathrm{nNOS}^{-/-}\right)$resulted in a delayed gastric emptying phenotype [14]. There is a plethora of data suggesting that NPY regulates the function of nNOS. Cheung et al [15] demonstrated that NPY increased NO signaling in rat hippocampal cultures and was responsible for the neuroproliferative effect. In support of this observation, it was reported that NPY increased the nNOS expression in the mouse hypothalamus by $147 \%$ [16]. Together, these studies suggest a direct relationship between the levels of NPY and nNOS.

This study sought to determine whether the neuropeptides, SP and NPY, and the NPY receptors contribute to GI complications in streptozotocin (STZ)-induced type I diabetic male rats, and whether NPY levels affect their nNOS expression. Because the pylorus has previously been reported to be significantly involved in the development of gastroparesis $[17,18]$, we measured the changes of NPY receptors and nNOS $\alpha$ levels in pyloric tissue lysates.

\section{Materials and Methods}

\section{Materials}

Virgin male Sprague-Dawley rats (200 - 250 g, 12 weeks old) were purchased from Charles River (San Diego, CA). All reagent-grade chemicals used were purchased from SigmaAldrich Inc. (St. Louis, IL), as was the monoclonal actin antibody $(\mathrm{mAb})$. The enzyme-linked immunosorbent assay (ELISA) kits for NPY and SP were purchased from Ray Biotech, Inc. (Norcross, GA) and Abcam (Eugene, OR), respectively. The monoclonal antibody for NPY-Y1 and the polyclonal antibody (pAb) for NPY-Y2 were purchased from Santa Cruz Biotechnology Inc. (Dallas, TX). The chromogenic assay kit to measure the total NOS activity was purchased from Oxford Biomedical Research (Rochester Hills, MI).

This study was reviewed and approved by the Institutional Animal Care and Use Committee and was conducted in compliance with all the applicable guidelines for the care, welfare and use of animals.

\section{Grouping and diabetes induction}

In this study, we used STZ-induced male diabetic rats, a welldocumented model of type I diabetes characterized by hyperglycemia and decreased insulin levels [17]. Diabetes was induced by a single intraperitoneal injection of $55 \mathrm{mg} / \mathrm{kg}$ of STZ (Sigma) in $0.1 \mathrm{M}$ of citrate buffer ( $\mathrm{pH} 4.5)$ after an overnight fast. Non-diabetic control animals (CM) were injected with $0.1 \mathrm{M}$ of citrate buffer only. During the treatment period (12 weeks), blood glucose was measured every 3 days using an Accu-Check ${ }^{\circledR}$ blood glucose meter (Roche Diagnostics, Basel, Switzerland). Rats with blood glucose levels $>300 \mathrm{mg} / \mathrm{dL}$ were considered diabetic. The male rat model of gastroparesis developed in our laboratory resulted in the following study groups: control (CM), diabetic (DM) and diabetic gastroparesis (DM + GP) after STZ treatment. We established the groups by changes in their serum levels of acetaminophen (measures altered gastric emptying): the higher the serum level at $3 \mathrm{~h}$ post gavage, the faster the gastric emptying time.

\section{Biochemical analyses}

The levels of SP and NPY were determined using ELISA kits according to the manufacturers' instructions. Protein in pylorus tissue lysates was estimated using the bicinchoninic acid (BCA) protein assay reagent (Thermo Fisher Scientific, Rockford, IL).

\section{Western blotting of NPY-Y1 and NPY-Y2}

Pylorus smooth muscle tissues were homogenized using commercially available tissue buffer (Thermo Fisher Scientific) containing protease inhibitors. Lysates were centrifuged at $15,000 \times \mathrm{g}$ for $15 \mathrm{~min}$ at $4{ }^{\circ} \mathrm{C}$ and the supernatant was collected. Equal amounts of protein $(40 \mu \mathrm{g})$ were loaded on an $8 \%$ sodium dodecyl sulphate-polyacrylamide gel electrophoresis (SDS-PAGE) and transferred to nitrocellulose membrane. NPY-Y1 and NPY-Y2 were detected using specific primary antibodies and IR800-conjugated secondary antibody. Actin was used as a loading control detected by incubation with antiactin mAb followed by IR680-conjugated secondary antibody. Both NPY-Y1 monoclonal antibody (anti-NPY-Y1 mAb) and NPY-Y2 polyclonal antibody (anti-NPY-Y2 pAb) were used at a dilution of 1:100, and the monoclonal actin antibody (antiactin $\mathrm{mAb}$ ) was used at a dilution of 1:10,000. NPY-Y2 was not detected under these experimental conditions. The level of NPY-Y1 was normalized to that of actin by densitometric analysis using LiCor Odyssey ${ }^{\mathrm{TM}}$ Infrared Imaging System (Lincoln, NE), and expressed as arbitrary units.

\section{Dimerization assays for $\mathrm{nNOS \alpha}$}

The catalytic activity of nNOS $\alpha$ depends on the dimerization of the two polypeptides of this protein. Low temperature SDSPAGE, which protects dimerization, was used to measure the 

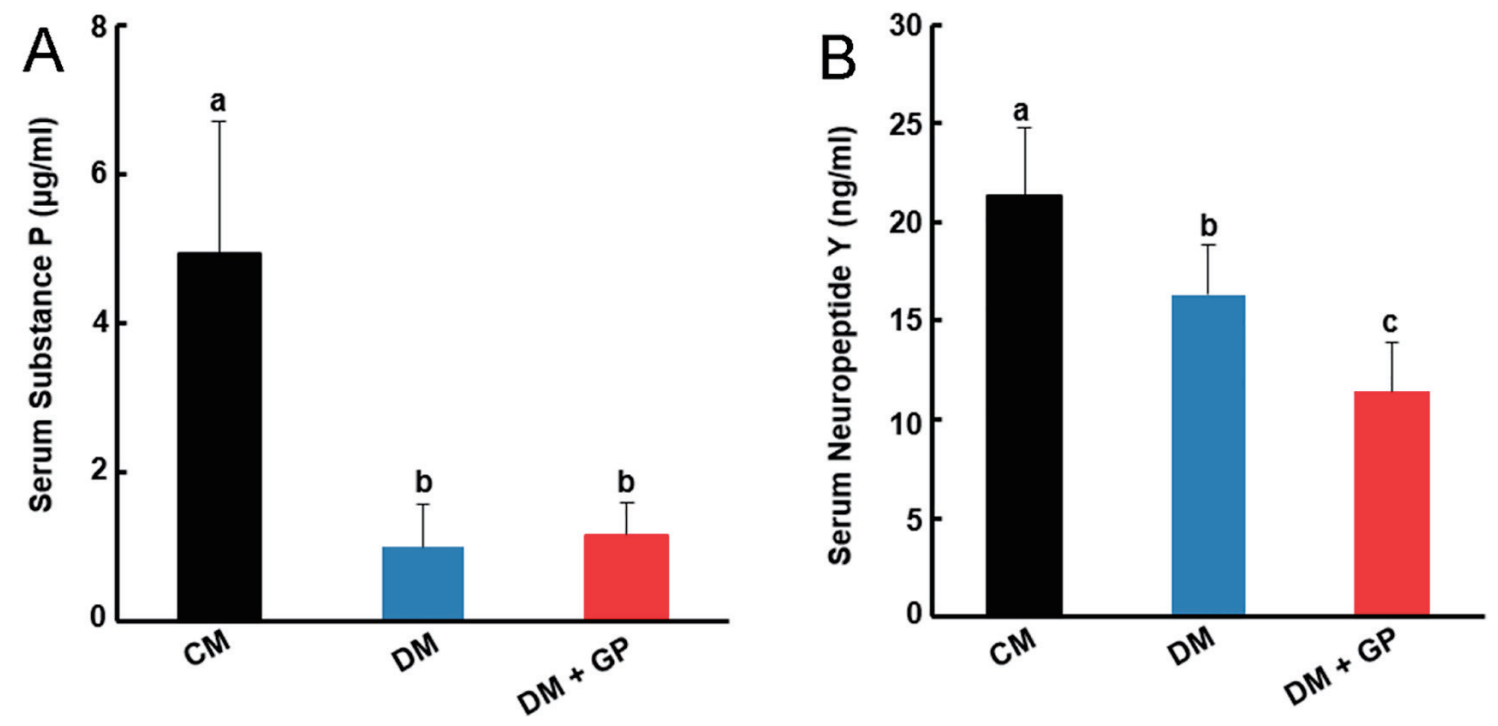

Figure 1. (A) Serum substance $P(S P)$. SP levels were decreased significantly in diabetic (DM, $(0.92 \pm 0.67 \mathrm{ng} / \mathrm{mL})$ and diabetic gastroparesis (DM + GP, $1.11 \pm 0.42 \mathrm{ng} / \mathrm{mL}$ ) compared to the control $(C M)$ group $(4.94 \pm 1.77 \mathrm{ng} / \mathrm{mL}$ ) (overall analysis of variance (ANOVA), $\mathrm{P}=0.001$, Newman Keuls (NK) post hoc comparisons at $\alpha=0.05$ ), with no significant difference between DM and $\mathrm{DM}+\mathrm{GP}$. (B) Neuropeptide Y (NPY) levels in CM, DM and DM + GP rats. NPY serum levels were decreased significantly in DM $(16.32 \pm 2.56 \mathrm{ng} / \mathrm{mL})$ and in $\mathrm{DM}+\mathrm{GP}(11.4 \pm 2.50 \mathrm{ng} / \mathrm{mL})$, as compared to CM group $(21.32 \pm 3.41 \mathrm{ng} / \mathrm{mL})$, with DM + GP significantly more decreased compared to DM (ANOVA, $\mathrm{P}=0.0005$, NK post hoc comparisons at $\alpha=0.05$ ). "b" indicates significant statistical difference compared to control "a". "c" indicates significant statistical difference compared to both "a" and "b." Data are expressed as the mean \pm standard deviation of five rats per group.

activity of $\mathrm{nNOS} \alpha$ as described previously [19]. Tissue lysates containing equal amounts of protein $(30 \mu \mathrm{g})$ were mixed with SDS-sample buffer and incubated on ice for $30 \mathrm{~min}$. The samples were then resolved on $7.5 \%$ SDS-PAGE. The proteins were transferred to a nitrocellulose membrane and western blotted with anti-nNOS $\alpha$ pAb followed by incubation with goat IRDye 800-conjugated anti-rabbit secondary antibody, and the image was captured using the OdysseyTM Infrared Imaging System. The electrophoresis and transfer were performed at $4{ }^{\circ} \mathrm{C}$ to ensure that the samples did not become warm during the procedure.

\section{Total NOS activity in the pylorus}

Total NOS activity was measured using a commercial NOS colorimetric assay kit. This kit measured the activity of the all the NOSs including iNOS, eNOS and nNOS in the tissue extract. Briefly, pyloric tissue lysate $(60 \mu \mathrm{g})$ was incubated with nitrate reductase and nicotinamide adenine dinucleotide (NADH) at $37{ }^{\circ} \mathrm{C}$ for overnight followed by addition of Griess reagent. The chromophore of the released nitrite was then measured spectrophotometrically at $540 \mathrm{~nm}$.

\section{Statistical analysis}

The data were expressed as the mean \pm standard deviation (STDEV) with 4 - 5 rats in each group. Statistical analysis was performed using the one-way analysis of variance (ANOVA) to test for differences in the group means, followed by a post hoc Newman-Keuls (NK) test if the ANOVA test was significant. P-values less than 0.05 were considered significant.

\section{Results}

SP and NPY serum levels in all animal groups were determined. Figure 1A demonstrates SP levels were decreased significantly in DM $(0.92 \pm 0.67 \mathrm{ng} / \mathrm{mL})$ and DM + GP $(1.11 \pm$ $0.42 \mathrm{ng} / \mathrm{mL})$ compared to the CM group $(4.94 \pm 1.77 \mathrm{ng} / \mathrm{mL})$ (overall ANOVA, $\mathrm{P}=0.001$, Newman Keuls (NK) post hoc comparisons at $\alpha=0.05$ ), with no significant difference between DM and DM + GP. As shown in Figure 1B, NPY serum levels were decreased significantly in DM (16.32 $\pm 2.56 \mathrm{ng} /$ $\mathrm{mL})$ rats and in $\mathrm{DM}+\mathrm{GP}(11.4 \pm 2.50 \mathrm{ng} / \mathrm{mL})$, as compared to CM control (21.32 $\pm 3.41 \mathrm{ng} / \mathrm{mL})$, with DM + GP significantly more decreased compared to DM (ANOVA, P $=0.0005$, NK post hoc comparisons at $\alpha=0.05$ ).

Localized expressions of NPY-Y1 and NPY-Y2 in the pylorus tissue were measured following western blotting. Pylorus NPY-Y2 was not detected, but NPY-Y1 expression (Fig. 2A) showed NPY-Y1 protein levels in the pylorus (compare lanes 1 - 4 with lanes 5 - 8 and 9 - 12, upper panel). Figure 2B shows the quantification of the protein band for NPY-Y1 as normalized with actin by densitometric analysis and expressed as arbitrary units. The level of NPY-Y1 was significantly upregulated in DM when compared to both CM and DM + GP (DM: $4.58 \pm 1.48 ; \mathrm{CM}: 1.31 \pm 0.60 ; \mathrm{DM}+\mathrm{GP}: 1.51 \pm 0.23$ (ANOVA, $\mathrm{P}=0.0012$, NK post hoc comparisons at $\alpha=0.05$ ). 

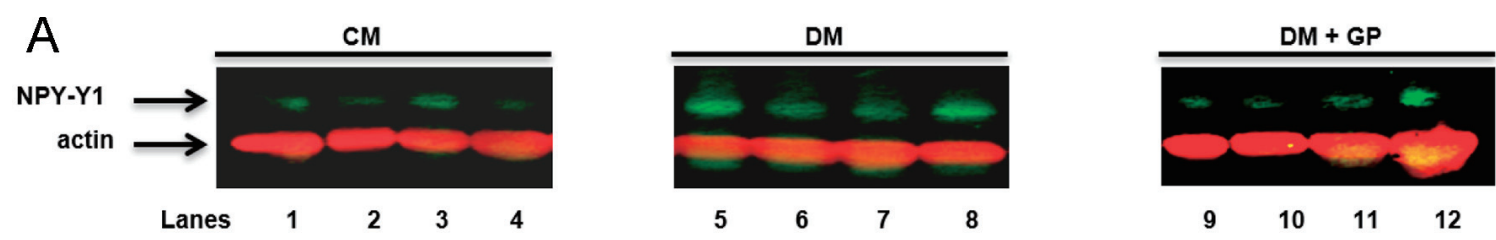

Immunoblot: NPY-Y1 mAb/ actin mAb

B

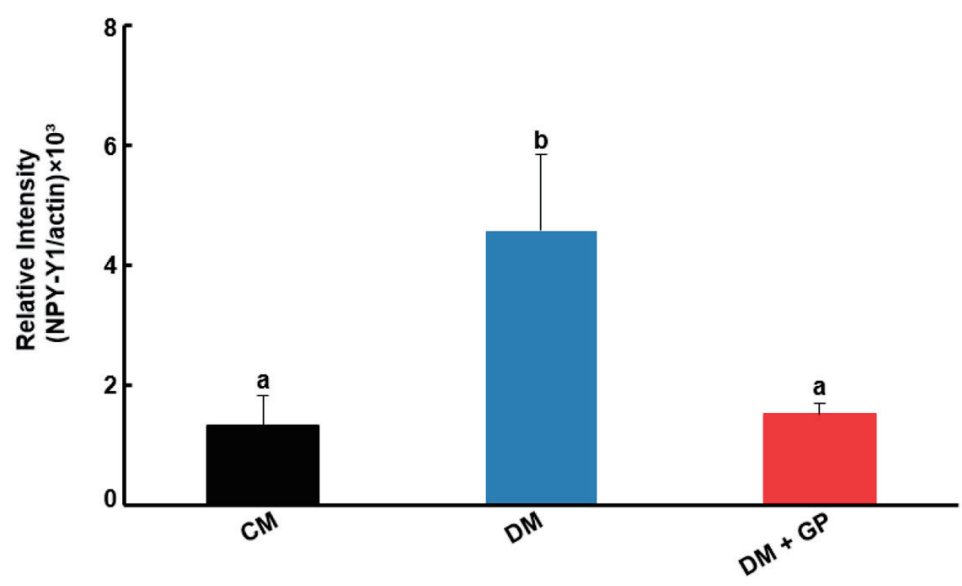

Figure 2. Neuropeptide receptor Y1 (NPY-Y1) level in pyloric tissue. (A) Representative immunoblot (IB) showing the level of NPY-Y1 and actin as indicated by the arrows. (B) The relative intensities of the NPY-Y1 protein were shown to be increased in diabetic ( $\mathrm{DM}, 4.58 \pm 1.48)$ compared to control $(\mathrm{CM}, 1.31 \pm 0.60)$ and diabetic gastroparesis (DM + GP, $1.15 \pm 0.23)$ rats (analysis of variance (ANOVA), $\mathrm{P}=0.0012$, Newman Keuls (NK) post hoc comparisons at $\alpha=0.05$ ). Data are expressed as the mean \pm standard deviation of four rats per group. "b" indicates significant statistical difference compared to control "a". Data are expressed as the mean \pm standard error (SE) of four rats per group.

There was no change in the enzymatic activity of nNOS $\alpha$ as measured by the dimerization of the $\mathrm{nNOS} \alpha$ protein in either DM or DM + GP compared to the CM group (Fig. 3A, B, ANOVA, $\mathrm{P}=0.732$ ). We also measured the $\mathrm{nNOS} \alpha$ protein levels in pyloric tissue lysate following western blotting and found no significant changes in nNOS $\alpha$ protein levels between any of the three groups (ANOVA, $\mathrm{P}=0.38$, data not shown). The total NOS activity was, as well, not statistically significant regardless of the rat group and NPY levels (ANOVA, $\mathrm{P}=0.26$, data not shown).

\section{Discussion}

In the present study, we determined the serum levels of NPY and $\mathrm{SP}$ in CM, DM and DM + GP male rats. Our results suggest that decreased SP levels are involved in the pathogenesis of both diabetes and diabetic gastroparesis in this type I diabetes model, as both groups (DM and DM + GP) compared to CM rats showed significantly decreased SP. Similarly, a study from the Gastroparesis Clinical Research Consortium reported that SP immunolabeling was decreased in four of the five gastroparetic patients studied [20].

NPY levels as well were significantly decreased in both
$\mathrm{DM}$ and DM + GP rats. However, NPY levels were more significantly decreased in DM + GP compared to both CM and DM rats, indicating that severe NPY depletion might be a pathogenic factor associated with gastroparesis phenotype in our rat model.

Although there are differences in expression and distribution of the NPY receptors among the rat, mouse and human species [21], NPY transmits signal through binding to any of the five (Y1, Y2, Y4, Y5 and Y6) mammalian G-protein coupled receptors, and their interactions are essential for physiological outcome [22]. NPY-Y1 and NPY-Y2 receptors are well studied receptors involved in diabetes and obesity [23, 24]. The physiological functions of NPY-Y1, in coordination with Y5 receptor, include energy homeostasis, induction of fasting-induced food intake and hyperphagia in mice [25]. NPY-Y2 is widely distributed and associated with a number of diseases including diabetes, heart failure, hypertension, peripheral arterial disease and congestive feeding disorders in humans [26]. Given the importance of $\mathrm{Y} 1$ and $\mathrm{Y} 2$ receptors in various physiological functions, and given that our results indicated a significantly decreased NPY level in the DM + GP rats, we hypothesized that NPY-Y1 and/or NPY-Y2 may be critically important for maintaining gastric motility. We therefore examined their receptor expressions. NPY-Y2 levels were not detected in our 

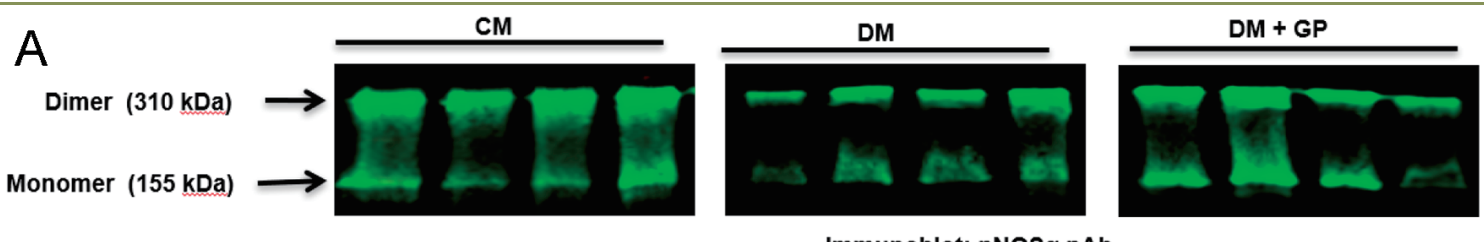

Immunoblot: nNOSa pAb

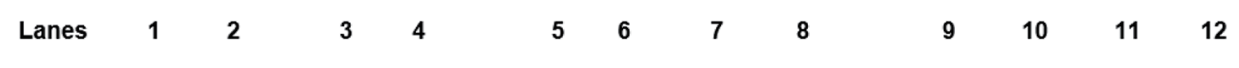

\section{B}

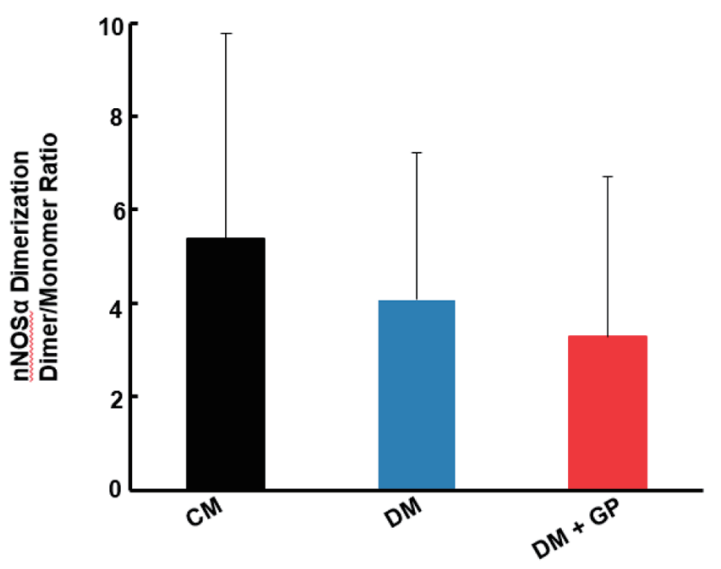

Figure 3. Dimerization of neuronal nitric oxide synthase alpha (nNOSa) in the pylorus of male rats. (A) Representative immunoblot (IB) showing the formation of dimer (310 kDa) and monomer (155 kDa) nNOSa in pylorus tissue. (B) Densitometric analysis data of the dimerization of nNOSa expressed as the ratio of dimer to monomer. Data are expressed as the mean \pm standard error (SE) of four rats per group. There are no significant changes in the levels of dimerization of nNOSa in any of the rat groups examined (analysis of variance (ANOVA), $\mathrm{P}=0.732$ ).

study, however, possibly due to low abundance or lack of de novo synthesis in pyloric tissue. It is also possible that specific antibody (NPY-Y2) which has not previously tested for pyloric tissue, may not be sensitive enough to detect this protein.

NPY-Y1 expression, however, was detected and showed significantly increased levels in DM, but not in DM + GP rats, suggesting that higher expression levels of NPY-Y1 might be associated with diabetes but not with the gastroparesis phenotype. Upregulation of this receptor, which is necessary for NPY to elicit its physiological effects, might protect the diabetic rats from development of further gastric motility complications.

Takahashi et al reported that impaired nNOS synthesis of the myenteric plexus is an important contributing factor to the pathogenesis of gastroparesis [27]. Saur et al [28] reported the expression of three distinct isomers of $\mathrm{nNOS}$ proteins in the human gut: $\mathrm{nNOS} \alpha, \mathrm{nNOS} \beta$ and $\mathrm{nNOS} \gamma$. Among these isomers, the altered expression and/or biological activity of nNOS $\alpha$ is associated with several GI disorders, including altered gastric motility in female rats $[19,29]$. The catalytically active $\mathrm{nNOS} \alpha$ is a dimerized protein, and loss of dimerization can lead to delayed gastric emptying, as has been reported in the antrum [19, 29] and pylorus [19] of STZ-induced diabetic gastroparetic rats. To elucidate whether the reduced serum level of NPY in DM + GP rats as observed in this study is associated with the impairment of dimerization of $n N O S \alpha$, we examined the level of $\mathrm{nNOS} \alpha$ and dimerization in rat pyloric tissues and found that the decreased level of NPY in DM +
GP rats is independent of $\mathrm{nNOS} \alpha$ level and dimerization. Our data also suggest that the development of gastroparesis is not associated with the activity of total NOS in male diabetic rats, regardless of NPY levels.

We hypothesize from our data that impaired gastric emptying in this male diabetic type I rat model is associated with a severely decreased NPY level with no upregulation of NPYY1. However, some limitations need to be acknowledged. We studied the role of only two important neuropeptides. Marked changes in specific enteric neuropeptides, including motilin, VIP and somatostatin, have also been observed in experimental animal models of diabetes. The regulation of NPY levels by five mammalian G-protein coupled receptors [22] appears to be part of a complex system and deserves further investigation. Furthermore, the direct link between the decreased level of NPY and gastroparesis in this model is unknown. Additional studies are required to elucidate the causal relationship between the level of NPY and gastric motility dysregulation. As well, lack of detection of NPY-Y2 needs to be further investigated in terms of tissue specific antibody sources. The pylorus contains an outer longitudinal layer and an inner circular layer muscle, gastric pits, mucosa, parietal cells and neuroendocrine cells. Because we used the total pyloric tissue lysate for this study, we could not determine what individual components in the lysate were responsible for the observed changes in diabetic gastroparesis.

Despite these limitations, the current findings reveal a 
previously unrecognized association of severely decreased NPY with diabetic gastroparesis phenotype. Based on these findings, we hypothesize that the dysregulation of NPY and/ or activation/deactivation of the NPY signaling pathways can positively or negatively affect neuroendocrine homeostasis. Targeting NPY and its signaling pathways might serve as a new therapeutic direction for the treatment of gastroparesis.

\section{Acknowledgments}

We thank Dr. Julia Bader for the statistical analyses of the data.

\section{Financial Disclosure}

This work was supported by the intramural funding from William Beaumont Army Medical Center, Ft. Bliss, TX.

\section{Conflict of Interest}

The authors declare no potential conflict of interest.

\section{Informed Consent}

Informed consent is not required for non-human studies.

\section{Author Contributions}

MSA conceptualized the study, analyzed the data and wrote the manuscript. RS conducted experiments, provided technical assistance and helped finalize the manuscript. RM participated in the project design, coordinated the study and helped finalize the manuscript. All authors have read and approved the manuscript.

\section{Data Availability}

The authors declare that data supporting the findings of this study are available within the article.

\section{References}

1. Parkman HP, Fass R, Foxx-Orenstein AE. Treatment of patients with diabetic gastroparesis. Gastroenterol Hepatol (N Y). 2010;6(6):1-16.

2. El-Salhy M. Gastrointestinal transit in an animal model of human diabetes type 2: relationship to gut neuroendocrine peptide contents. Ups J Med Sci. 2002;107(2):101110.

3. El-Salhy M, Spangeus A. Gastric emptying in animal models of human diabetes: correlation to blood glucose level and gut neuroendocrine peptide content. Ups J Med
Sci. 2002;107(2):89-99.

4. Matsuda M, Aono M, Moriga M, Okuma M. Centrally administered neuropeptide Y (NPY) inhibits gastric emptying and intestinal transit in the rat. Dig Dis Sci. 1993;38(5):845-850.

5. Holzer P, Holzer-Petsche U. Tachykinins in the gut. Part I. Expression, release and motor function. Pharmacol Ther. 1997;73(3):173-217.

6. Kunt T, Forst T, Schmidt S, Pfutzner A, Schneider S, Harzer O, Lobig M, et al. Serum levels of substance P are decreased in patients with type 1 diabetes. Exp Clin Endocrinol Diabetes. 2000;108(3):164-167.

7. Iwasaki H, Kajimura M, Osawa S, Kanaoka S, Furuta T, Ikuma M, Hishida A. A deficiency of gastric interstitial cells of Cajal accompanied by decreased expression of neuronal nitric oxide synthase and substance $\mathrm{P}$ in patients with type 2 diabetes mellitus. J Gastroenterol. 2006;41(11):1076-1087.

8. Pedragosa-Badia X, Stichel J, Beck-Sickinger AG. Neuropeptide Y receptors: how to get subtype selectivity. Front Endocrinol (Lausanne). 2013;4:5.

9. Imai Y, Patel HR, Hawkins EJ, Doliba NM, Matschinsky FM, Ahima RS. Insulin secretion is increased in pancreatic islets of neuropeptide Y-deficient mice. Endocrinology. 2007;148(12):5716-5723.

10. Lin EJ, Sainsbury A, Lee NJ, Boey D, Couzens M, Enriquez $\mathrm{R}$, Slack $\mathrm{K}$, et al. Combined deletion of $\mathrm{Y} 1, \mathrm{Y} 2$, and Y4 receptors prevents hypothalamic neuropeptide Y overexpression-induced hyperinsulinemia despite persistence of hyperphagia and obesity. Endocrinology. 2006;147(11):5094-5101.

11. Adeghate E, Ponery AS, Pallot DJ, Singh J. Distribution of vasoactive intestinal polypeptide, neuropeptide-Y and substance $\mathrm{P}$ and their effects on insulin secretion from the in vitro pancreas of normal and diabetic rats. Peptides. 2001;22(1):99-107.

12. Qin XY, Wang ZG, Fei J, Liu FL, Cui DF, Chen SL. Involvement of dopamine D3 and neuropeptide Y Y5 receptors in diabetic gastroparetic rats without response to erythromycin. Sheng Wu Hua Xue Yu Sheng Wu Wu Li Xue Bao (Shanghai). 2003;35(9):811-815.

13. Gangula PR, Sekhar KR, Mukhopadhyay S. Gender bias in gastroparesis: is nitric oxide the answer? Dig Dis Sci. 2011;56(9):2520-2527.

14. Mashimo H, Kjellin A, Goyal RK. Gastric stasis in neuronal nitric oxide synthase-deficient knockout mice. Gastroenterology. 2000;119(3):766-773.

15. Cheung A, Newland PL, Zaben M, Attard GS, Gray WP. Intracellular nitric oxide mediates neuroproliferative effect of neuropeptide y on postnatal hippocampal precursor cells. J Biol Chem. 2012;287(24):20187-20196.

16. Morley JE, Alshaher MM, Farr SA, Flood JF, Kumar VB. Leptin and neuropeptide Y (NPY) modulate nitric oxide synthase: further evidence for a role of nitric oxide in feeding. Peptides. 1999;20(5):595-600.

17. Crimmins S, Smiley R, Preston K, Yau A, McCallum R, Ali MS. Increased Expression of Pyloric ERbeta Is Associated With Diabetic Gastroparesis in StreptozotocinInduced Male Diabetic Rats. Gastroenterology Res. 
2016;9(2-3):39-46.

18. Moraveji S, Bashashati M, Elhanafi S, Sunny J, Sarosiek I, Davis B, Torabi A, et al. Depleted interstitial cells of Cajal and fibrosis in the pylorus: Novel features of gastroparesis. Neurogastroenterol Motil. 2016;28(7):10481054.

19. Showkat Ali M, Tiscareno-Grejada I, Locovei S, Smiley R, Collins T, Sarosiek J, McCallum R. Gender and estradiol as major factors in the expression and dimerization of nNOSalpha in rats with experimental diabetic gastroparesis. Dig Dis Sci. 2012;57(11):2814-2825.

20. Grover M, Farrugia G, Lurken MS, Bernard CE, Faussone-Pellegrini MS, Smyrk TC, Parkman HP, et al. Cellular changes in diabetic and idiopathic gastroparesis. Gastroenterology. 2011;140(5):1575-1585 e1578.

21. Dumont Y, Jacques D, Bouchard P, Quirion R. Species differences in the expression and distribution of the neuropeptide Y Y1, Y2, Y4, and Y5 receptors in rodents, guinea pig, and primates brains. J Comp Neurol. 1998;402(3):372-384.

22. Yi M, Li H, Wu Z, Yan J, Liu Q, Ou C, Chen M. A promising therapeutic target for metabolic diseases: neuropeptide Y receptors in humans. Cell Physiol Biochem. 2018;45(1):88-107.

23. Parker SL, Balasubramaniam A. Neuropeptide Y Y2 receptor in health and disease. Br J Pharmacol. 2008; 153(3):420-431.

24. Pedrazzini T. Importance of NPY Y1 receptor-mediated pathways: assessment using NPY Y1 receptor knockouts. Neuropeptides. 2004;38(4):267-275.

25. Nguyen AD, Mitchell NF, Lin S, Macia L, Yulyaningsih E, Baldock PA, Enriquez RF, et al. Y1 and Y5 receptors are both required for the regulation of food intake and energy homeostasis in mice. PLoS One. 2012;7(6):e40191.

26. Ejaz A, LoGerfo FW, Khabbaz K, Pradhan L. Expression of Neuropeptide Y, Substance P, and their receptors in the right atrium of diabetic patients. Clin Transl Sci. 2011;4(5):346-350.

27. Takahashi T. Pathophysiological significance of neuronal nitric oxide synthase in the gastrointestinal tract. J Gastroenterol. 2003;38(5):421-430.

28. Saur D, Paehge H, Schusdziarra V, Allescher HD. Distinct expression of splice variants of neuronal nitric oxide synthase in the human gastrointestinal tract. Gastroenterology. 2000;118(5):849-858.

29. Gangula PR, Maner WL, Micci MA, Garfield RE, Pasricha PJ. Diabetes induces sex-dependent changes in neuronal nitric oxide synthase dimerization and function in the rat gastric antrum. Am J Physiol Gastrointest Liver Physiol. 2007;292(3):G725-733. 